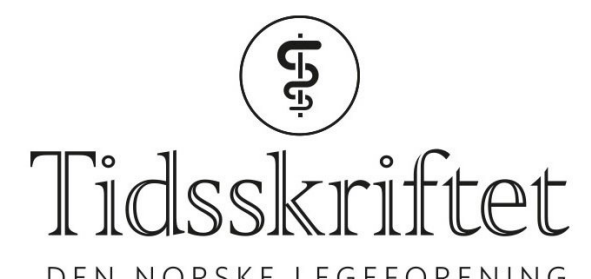

DEN NORSKE LEGEFORENING

\title{
Psykedeliske stoffer i behandling av angst, depresjon og avhengighet
}

OVERSIKTSARTIKKEL

\section{TOR-MORTEN KVAM}

E-post: tor-morten.kvam@so-hf.no Nordre Østfold DPS

Moss poliklinikk

Sykehuset Østfold

Han har bidratt med litteratursøk, utarbeiding og revisjon av mesteparten av manuset.

Tor-Morten Kvam er spesialist i psykiatri og overlege.

Forfatter har fylt ut ICMJE-skjemaet og oppgir følgende interessekonflikter: Han er involvert i en internasjonal klinisk studie med psilocybin mot behandlingsresistent depresjon med planlagt oppstart høsten 2018. Studien er finansiert av Compass Pathways, som jobber for å innføre evidensbaserte metoder i psykisk helsevern.

\section{LOWAN H. STEWART}

Santa Fe Ketamine Clinic

CSV Regional Medical Center

Santa Fe, USA

og

Sykehuset Østfold

Han har bidratt med konsept, utarbeiding/revisjon av manus og litteratursøk.

Lowan H. Stewart er spesialist i akuttmedisin.

Forfatteren har fylt ut ICMJE-skjemaet og oppgir følgende interessekonflikter: Han har hatt et ubetalt engasjement for tre år siden som medisinsk rådgiver i EmmaSofia. Forfatteren er involvert i en internasjonal klinisk studie med psilocybin mot behandlingsresistent depresjon med planlagt oppstart høsten 2018. Studien er finansiert av Compass Pathways, som jobber for å innføre evidensbaserte metoder i psykisk helsevern.

\section{OLE A. ANDREASSEN}

\section{SFF NORMENT}

Universitetet i Oslo

og

Oslo universitetssykehus

Han har bidratt med utarbeiding/revisjon av manus og godkjenning av innsendte manusversjon. Ole A. Andreassen er spesialist i psykiatri, professor og overlege.

Forfatteren har fylt ut ICMJE-skjemaet og oppgir følgende interessekonflikter: Han har mottatt forelesningshonorar fra Lundbeck, men ikke knyttet til dette arbeidet. Han er involvert i en internasjonal klinisk studie med psilocybin mot behandlingsresistent depresjon med planlagt oppstart høsten 2018. Studien er finansiert av Compass Pathways, som jobber for å innføre evidensbaserte metoder i psykisk helsevern. 


\section{BAKGRUNN}

Det er $ø$ kt interesse for psykedeliske stoffer til bruk i behandling av psykiske lidelser. Stoffene regnes som trygge når de gis innenfor en klinisk ramme. Eldre studier fra før 1970 har metodologiske svakheter, men i de senere år har det kommet lovende resultater fra bruk ved unipolar depresjon, depresjon ved livstruende sykdom, angst og avhengighet. Formålet med denne litteraturgjennomgangen er å gi en oversikt over nyere resultater og disse studienes begrensninger.

\section{KUNNSKAPSGRUNNLAG}

Vi søkte i databasen PubMed etter kliniske studier fra perioden 1990-2017 med søkeordene angst, depresjon, avhengighet og psykedeliske stoffer. Kvaliteten på studiene ble så vurdert ut ifra metode og styrkeberegning.

\section{RESULTATER}

Søket ga 424 artikler, hvorav ni ble inkludert (fire om angst og depresjon ved livstruende sykdom, to om depresjon, to om avhengighetslidelse og én om tvangslidelse). To dobbeltblinde, randomiserte, kontrollerte fase II-studier med et moderat antall pasienter fant umiddelbar, markert og vedvarende effekt av én enkeltdose psilocybin mot angst og depresjon ved livstruende sykdom. De andre studiene hadde mer usikre resultater. Det var ingen alvorlige bivirkninger eller rapportering om avhengighet.

\section{FORTOLKNING}

Psykedeliske stoffer i behandling av flere psykiske lidelser har vist lovende resultater, men studiene er små og har metodologiske utfordringer. Det er behov for systematiske kliniske studier for å skaffe solid dokumentasjon for effekt og etablere rutiner for overvåkning av mulige bivirkninger.

I 1950- og 6o-årene ble de klassiske psykedeliske stoffene lysergsyredietylamid (LSD) og psilocybin undersøkt i mange kliniske studier. Disse antydet effekt ved angst og depresjon ved livstruende sykdom, unipolare depresjoner og avhengighet (1-3). I en åpen studie av LSD hos kreftpasienter fant man bedring av ulike symptomer som smerte, angst og depresjon og økt aksept for døden hos omtrent $70 \%$ (1). En gjennomgang av psykedeliske stoffers effekt på unipolar depresjon i åpne studier viste rundt 8o \% bedring (2). En metaanalyse av randomiserte studier av LSD ved alkoholmisbruk viste signifikant effekt av LSD i forhold til kontrollgruppen, med oddsratio 1,96 (3). Behandling og forskning på psykedeliske stoffer tok slutt rundt 1970 som følge av internasjonal lovgivning (4). Psykedeliske stoffer er klassifisert av FN blant stoffer med misbrukspotensial og alvorlige helseskadelige effekter og uten terapeutisk potensial, men denne klassifiseringen har blitt kritisert (5).

Klassiske psykedeliske stoffer er syntetiske (som LSD) eller naturlig forekommende, slik som psilocybin fra fleinsopp, N,N-dimetyltryptamin (DMT) fra urtedrikken ayahuasca, og meskalin fra peyotekaktus. De er alle serotoninreseptoragonister og stimulerer hovedsakelig 5 -hydroksytryptamin $(\mathrm{HT})_{2 \mathrm{~A}}$-reseptoren $(4,6)$. Klassiske psykedeliske stoffer gir endret persepsjon, særlig visuell, affektive endringer i både retning av ekstase og angst, endret tidsoppfatning, audiovisuell synestesi, derealisasjon og depersonalisering, samt pseudohallusinasjoner (dvs. hallusinasjoner der virkelighetsoppfatningen er bevart) (7). Virkningen av de mest unders $\varnothing$ kte psykedeliske stoffene, psilocybin og LSD, varer i henholdsvis ca. 6 og 12 timer (4). Repetert bruk fører til toleranse på grunn av 5- $\mathrm{HT}_{2 \mathrm{~A}^{-}}$ reseptornedregulering (4).

Det har vært hevdet at klassiske psykedeliske stoffer kan gi farlige bivirkninger, men dette stammer fra studier med usikker metodologi (4). Systematiske studier til nå viser at de har 
lav toksisitet og høy terapeutisk indeks (4). Klassiske psykedeliske stoffer gir minimal fare for avhengighet (4). I en rangering av 20 legale og illegale substanser ut ifra skadevirkning på den enkelte bruker og samfunnet, var alkohol det verste, mens psilocybin og LSD var blant de minst skadelige (5). Det ses liten påvirkning av dopaminerge systemer, noe som kan forklare lav risiko for utvikling av avhengighet (4). Samtidig er det kasusrapporter om alvorlige, men sjeldne og hovedsakelig forbigående bivirkninger, slik som rabdomyolyse, iskemi i underekstremitetene og kortikal blindhet etter rekreasjonsbruk (4). Bruk av psykedeliske stoffer med ukontrollert styrke og renhetsgrad og ofte samtidig bruk av flere psykoaktive stoffer kompliserer fortolkningen av slike kasusrapporter (4). Videre virker risikoen for disse komplikasjonene lav i en kontrollert klinisk situasjon. I moderne kliniske studier av klassiske psykedeliske stoffer på selekterte pasientgrupper har man ikke sett disse bivirkningene (8-16).

Hallusinogenpersistent persepsjonsforstyrrelse (Hallucinogen Persisting Perception Disorder, HPPD) er en tilstand som har vært hovedsakelig assosiert med rekreasjonsbruk av LSD (17). Tilstanden kjennetegnes av at akutte persepsjoner gjenoppleves lenge etter akutt påvirkning av stoffet. Tilstanden har ukjent utbredelse, men den regnes som sjelden. Studier av tilstanden har metodologiske svakheter og baserer seg mye på kasusrapporter (17), og den har ikke blitt sett i de moderne studiene på feltet (8-16). En amerikansk studie med 130 ooo deltagere, hvor 13,4\% oppga aktuelt og/eller tidligere bruk av psykedelika (LSD, psilocybin eller meskalin), viste ingen sammenheng mellom bruk og psykiske vansker (18). En nyere og større populasjonsstudie fant at risiko for psykiske plager inklusive selvmordstanker var redusert blant brukere av klassiske psykedeliske stoffer, mens den var $\emptyset \mathrm{kt}$ hos brukere av andre illegale midler (19).

\section{Metode}

Vi gjorde en litteraturgjennomgang av behandling av psykiske lidelser med klassiske psykedeliske stoffer. PubMed ble brukt for å identifisere relevante artikler. Søket ble avgrenset til perioden 1.1.1990-31.12.2017 for å sikre fokus på moderne studier som benytter metoder som er i samsvar med gjeldende standarder for evidensbasert medisin. Vi brukte søkeordene «anxiety» OR «depression» OR «addiction», i kombinasjon med «psilocybin» OR «LSD» OR «DMT» OR «mescaline». Søkeprosedyre er gjengitt i figur 1. De identifiserte artiklene ble gjennomgått manuelt på følgende måte: Inklusjonskriterier var engelskspråklige originalartikler hvor det var gjennomført kliniske studier på pasienter. Eksklusjonskriterier var populasjonsstudier, oversiktsartikler og studier på friske frivillige. Andre stoffer med psykedeliske egenskaper, slik som f.eks. ketamin og MDMA (3,4metylendioksymetamfetamin), er ikke tatt med. Alle studiene som er gjennomgått $\mathrm{i}$ resultatdelen, ble identifisert gjennom overnevnte søk.

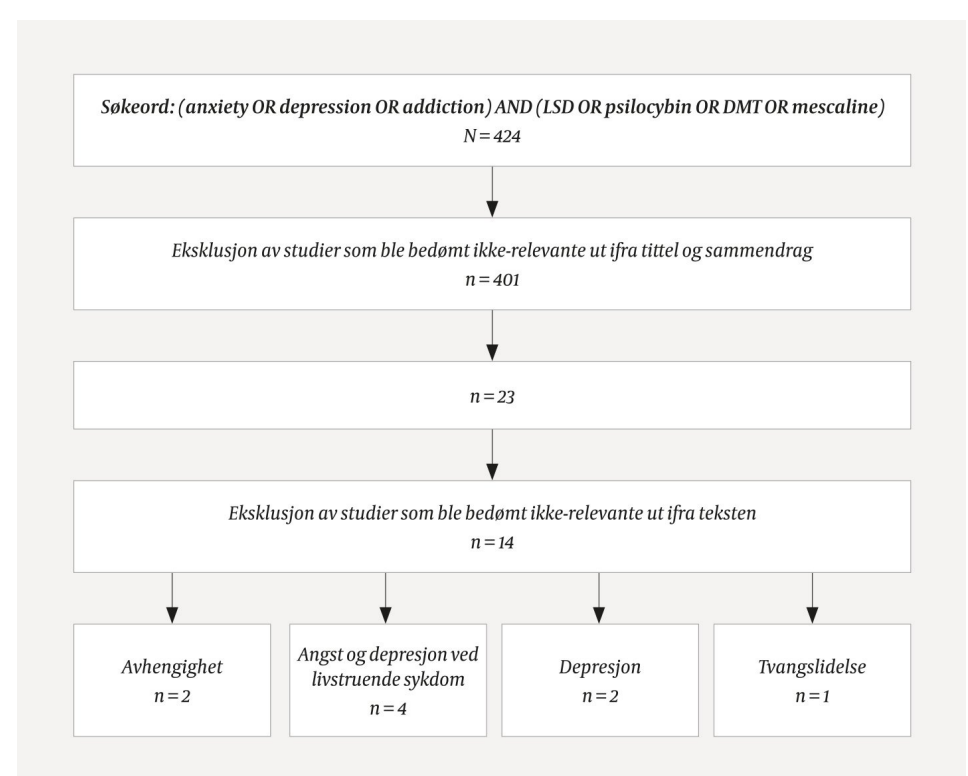

Figur 1 Flytdiagrammet viser kunnskapsgrunnlaget $i$ denne oversiktsartikkelen som er basert på ni 


\section{Resultater}

Av i alt 424 artikler fylte ni inklusjonskriteriene (8-16). Disse fordelte seg på de fire hovedkategoriene angst og depresjon ved livstruende sykdom (4 studier), depresjon (2 studier), avhengighet (2 studier) og tvangslidelse (1 studie). I alle studiene administrerte man psykedeliske stoffer integrert med psykologisk behandling. Studiene er oppsummert i tabell 1.

\section{Tabell 1}

Oversikt over og sammenligning av de ni studiene som ble identifisert gjennom litteratursøket. HAM-A: Hamilton Anxiety Rating Scale; HAMD: Hamilton Rating Scale For Depression; HADS: Hospital Anxiety and Depression Scale; STAI: State-Trait Anxiety Inventory; BDI: Becks Depression Inventory; QIDS: Quick Inventory of Depressive Symptoms; YBOCS: Yale-Brown Obsessive Compulsive Scale.

\begin{tabular}{|c|c|c|c|c|c|c|c|}
\hline Studie & $\begin{array}{l}\text { Antall pasienter, } \\
\text { tilstand }\end{array}$ & Design, oppfølgingstid & $\begin{array}{l}\text { Intervensjonsgrupp } \\
\text { vs. kontrollgruppe }\end{array}$ & $\begin{array}{l}\text { Primære } \\
\text { endepunkter }\end{array}$ & Responsrate & Remisjonsrate & Effektstørrelse $^{1}$ \\
\hline Ross 2016 (14) & $\begin{array}{l}29 \text {, angst og } \\
\text { depresjon ved } \\
\text { livstruende kreft }\end{array}$ & $\begin{array}{l}\text { Randomisert kontrollert } \\
\text { dobbeltblind } \\
\text { overkrysnings-studie, } \\
6 \mathrm{md}\end{array}$ & $\begin{array}{l}\text { Psilocybin } \\
(0,3 \mathrm{mg} / \mathrm{kg}) \\
\text { vs. } \\
\text { niacin } 250 \mathrm{mg}\end{array}$ & $\begin{array}{l}\text { HADS } \\
\text { (angst og } \\
\text { depresjon) } \\
\text { BDI } \\
\text { (depresjon) } \\
\text { STAI (angst) }\end{array}$ & $\begin{array}{l}\text { BDI: } \\
\text { Psilocybin: } \\
83 \% \\
\text { Niacin: } \\
14 \% \\
\text { HADS-A: } \\
\text { Psilocybin: } \\
58 \% \\
\text { Niacin: } \\
14 \% \\
\end{array}$ & $\begin{array}{l}\text { BDI: } \\
\text { Psilocybin: > } \\
80 \% \\
\text { Niacin: < } \\
20 \%\end{array}$ & $\begin{array}{l}\text { Ulike effekt- } \\
\text { størrelser } \\
\text { for ulike } \\
\text { endepunkter: } \\
0,80-1,69 \text { før } \\
\text { overkrysning }^{2}\end{array}$ \\
\hline $\begin{array}{l}\text { Griffiths } 2016 \\
\text { (10) }\end{array}$ & $\begin{array}{l}\text { 51, angst og } \\
\text { depresjon ved } \\
\text { livstruende kreft }\end{array}$ & $\begin{array}{l}\text { Randomisert kontrollert } \\
\text { dobbeltblind } \\
\text { overkrysnings-studie, } \\
6 \mathrm{md}\end{array}$ & $\begin{array}{l}\text { Psilocybin } \\
\text { (0,3 eller } \\
0,4 \mathrm{mg} / \mathrm{kg}) \\
\text { vs. } \\
\text { psilocybin } \\
\text { (0,01 eller } \\
0,04 \mathrm{mg} / \mathrm{kg})\end{array}$ & $\begin{array}{l}\text { HAMD } \\
\text { (depresjon) } \\
\text { HAM-A } \\
\text { (angst) }\end{array}$ & $\begin{array}{l}\text { HAMD: } \\
\text { Høydose: } \\
92 \% \\
\text { Lavdose: } \\
32 \% \\
\text { HAM-A: } \\
\text { Høydose: } \\
76 \% \\
\text { Lavdose: } \\
24 \% \\
\end{array}$ & $\begin{array}{l}\text { HAMD: } \\
\text { Høydose: } \\
60 \% \\
\text { Lavdose: } \\
16 \% \\
\text { HAM-A: } \\
\text { Høydose: } \\
52 \% \\
\text { Lavdose: } \\
12 \% \\
\end{array}$ & $\begin{array}{l}0,82 \text { før } \\
\text { overkrysning. } \\
\text { Begge grupper } \\
6 \text { md etter } \\
\text { behandling } \\
\text { sammenlignet } \\
\text { med } \\
\text { utgangspunktet: } \\
1,55^{2}\end{array}$ \\
\hline Grob 2011 (11) & $\begin{array}{l}\text { 12, angst ved } \\
\text { avansert } \\
\text { kreftsykdom }\end{array}$ & $\begin{array}{l}\text { Kontrollert dobbeltblind } \\
\text { Overkrysnings-pilotstudie, } \\
6 \mathrm{md}\end{array}$ & $\begin{array}{l}\text { Psilocybin } \\
(0,2 \mathrm{mg} / \mathrm{kg}) \\
\text { vs. } \\
\text { niacin } 250 \mathrm{mg}\end{array}$ & $\begin{array}{l}\text { Flere } \\
\text { parametere, } \\
\text { men ikke et } \\
\text { klart } \\
\text { definert } \\
\text { primært } \\
\text { endepunkt }\end{array}$ & $\begin{array}{l}\text { Ikke } \\
\text { oppgitt }\end{array}$ & Ikke oppgitt & Ikke oppgitt \\
\hline $\begin{array}{l}\text { Gasser } 2014 \\
\text { (16) }\end{array}$ & $\begin{array}{l}\text { 12, angst ved } \\
\text { livstruende sykdom }\end{array}$ & $\begin{array}{l}\text { Randomisert kontrollert } \\
\text { dobbeltblind pilotstudie, } \\
12 \mathrm{md}\end{array}$ & $\begin{array}{l}\text { LSD } 200 \mu \mathrm{g} \\
\text { vs. } \\
\text { LSD } 20 \mu \mathrm{g}\end{array}$ & $\begin{array}{l}\text { STAI } \\
\text { (tilstands- } \\
\text { og } \\
\text { trekkangst) } \\
\end{array}$ & $\begin{array}{l}\text { Ikke } \\
\text { oppgitt }\end{array}$ & Ikke oppgitt & $\begin{array}{l}\text { Tilstandsangst: } \\
1,2^{2} \\
\text { Trekkangst: } 1,1^{2}\end{array}$ \\
\hline $\begin{array}{l}\text { Carhart-Harris } \\
2016 \text { (9) }\end{array}$ & 12, depresjon & $\begin{array}{l}\text { Åpen pilotstudie, } \\
3 \mathrm{md}\end{array}$ & $\begin{array}{l}\text { Psilocybin } \\
10 \text { og } 25 \mathrm{mg} . \\
\text { Ingen } \\
\text { kontrollgruppe }\end{array}$ & QIDS & $67 \%$ & $58 \%$ & $\begin{array}{l}\text { 3,1 én uke og 2,0 } \\
\text { tre md etter } \\
\text { behandling } \\
\text { sammenlignet } \\
\text { med } \\
\text { utgangsverdi }{ }^{3}\end{array}$ \\
\hline $\begin{array}{l}\text { Osório } 2015 \\
\text { (15) }\end{array}$ & 6, depresjon & $\begin{array}{l}\text { Åpen pilotstudie, } \\
3 \text { uker }\end{array}$ & $\begin{array}{l}\text { Ayahuasca } \\
(2,2 \mathrm{ml} / \mathrm{kg})^{4} \\
\text { Ingen } \\
\text { kontrollgruppe }\end{array}$ & $\begin{array}{l}\text { Flere } \\
\text { parametere, } \\
\text { men ikke et } \\
\text { klart } \\
\text { definert } \\
\text { primært } \\
\text { endepunkt }\end{array}$ & $\begin{array}{l}\text { Ikke } \\
\text { oppgitt }\end{array}$ & Ikke oppgitt & Ikke oppgitt \\
\hline $\begin{array}{l}\text { Johnson } 2014 \\
\text { (12) }\end{array}$ & $\begin{array}{l}\text { 15, nikotin- } \\
\text { avhengighet }\end{array}$ & $\begin{array}{l}\text { Åpen pilotstudie, } \\
6 \mathrm{md}\end{array}$ & $\begin{array}{l}\text { Psilocybin } \\
0,3 \text { eller 0,4 mg/kg. } \\
\text { Ingen } \\
\text { kontrollgruppe }\end{array}$ & $\begin{array}{l}\text { Flere } \\
\text { parametere, } \\
\text { men ikke et } \\
\text { klart } \\
\text { definert } \\
\text { primært } \\
\text { endepunkt }\end{array}$ & $\begin{array}{l}\text { Ikke } \\
\text { oppgitt }\end{array}$ & Ikke oppgitt & Ikke oppgitt \\
\hline $\begin{array}{l}\text { Bogen-schutz } \\
2015(8)\end{array}$ & $\begin{array}{l}\text { 10, alkohol- } \\
\text { avhengighet }\end{array}$ & $\begin{array}{l}\text { Åpen pilotstudie, } \\
36 \text { uker }\end{array}$ & $\begin{array}{l}\text { Psilocybin } \\
0,3 \mathrm{mg} / \mathrm{kg} . \\
\text { Ingen } \\
\text { kontrollgruppe } \\
\end{array}$ & $\begin{array}{l}\text { Prosent } \\
\text { drikkedager }\end{array}$ & $\begin{array}{l}\text { Ikke } \\
\text { oppgitt }\end{array}$ & Ikke oppgitt & $0,75-1,38^{2}$ \\
\hline $\begin{array}{l}\text { Moreno } 2006 \\
\text { (13) }\end{array}$ & 9, tvangslidelse & $\begin{array}{l}\text { Pilotstudie, } \\
6 \mathrm{md}\end{array}$ & $\begin{array}{l}\text { Psilocybin } \\
0,025 \mathrm{mg} / \mathrm{kg}, \\
0,1 \mathrm{mg} / \mathrm{kg}, \\
0,2 \mathrm{mg} / \mathrm{kg} \text { og } \\
0,3 \mathrm{mg} / \mathrm{kg} \text {. } \\
\text { Ingen } \\
\text { kontrollgruppe }\end{array}$ & YBOCS & $\begin{array}{l}\text { Ikke } \\
\text { oppgitt }\end{array}$ & Ikke oppgitt & Ikke oppgitt \\
\hline
\end{tabular}

${ }^{1}$ Alle studiene viste signifikante forskjeller $(\mathrm{p}<0,05)$ på minst ett effektmål

${ }^{2}$ Cohens d

${ }^{3}$ Hegdes' g

${ }^{4}$ Drikken inneholdt o,8 mg/ml N,N-dimetyltryptamin (DMT) og o,21 mg/ml harmin 
Angst og depresjon øker sykeligheten og fremskynder død hos kreftpasienter. Tilgjengelige behandlingsalternativer er ofte ineffektive (10). I en dobbeltblind kontrollert overkrysningspilotstudie med 12 pasienter med angst og avansert kreftsykdom (11) fikk pasientene enten en moderat psilocybindose $(0,2 \mathrm{mg} / \mathrm{kg}$ ) eller niacin, som gir en mild fysiologisk reaksjon uten psykologisk påvirkning, før overkrysning. Depresjon målt med Becks depresjonsskala (Beck Depression Inventory, BDI) bedret seg etter psilocybinbehandling og ble signifikant etter seks måneder. Angst målt med State Trait Anxiety Inventory (STAI) ble også redusert, og nådde signifikans én og tre måneder etter behandling.

I en dobbeltblind randomisert kontrollert pilotstudie med 12 pasienter med angst og livstruende sykdom, hvorav de fleste (72,7\%) hadde kreft, ble effekten av $200 \mu \mathrm{g}$ eller $20 \mu \mathrm{g}$ LSD studert. Det ble demonstrert en positiv tendens til reduksjon av angst, både tilstandsangst/situasjonsbestemt angst (state anxiety) og trekkangst/personlighetsrelatert angst (trait anxiety) målt med STAI-skala. Reduksjonen av angst vedvarte ved oppfølging etter 12 måneder (16).

I en dobbeltblind randomisert kontrollert overkrysningsstudie fikk 51 kreftpasienter med livstruende sykdom og angst og/eller depresjon enten høydose eller lavdose psilocybin før overkrysning (10). Alle pasientene oppfylte kriteriene for en psykisk lidelse i henhold til Diagnostic and Statistical Manual of mental disorders IV (DSM-IV), inkludert tilpasningsforstyrrelse, generalisert angstlidelse, dystymi og depressiv episode. Alle pasientene fikk både lav- og høydose psilocybin med ca. fem ukers mellomrom. Det var signifikante forskjeller mellom gruppene: både reduksjon av depresjon og angst og økt livskvalitet og dødsaksept. Forskjellene ble bekreftet både av klinikere, pasientene selv og pårørende. De primære endepunktene på Hamiltons angstskala (Hamilton Anxiety Rating Scale, HAM-A) og Hamiltons depresjonsskala (Hamilton Rating Scale For Depression, HAMD) ble vurdert av klinikere. Resultatene vedvarte ved oppfølging seks måneder etter behandling: 77-83\% av pasientene viste respons og 59-71\% var i remisjon. Blindingstiltak ga en viss beskyttelse mot forventningseffekter.

I en dobbeltblind randomisert kontrollert overkrysningsstudie fikk 29 pasienter med kreftrelatert angst og depresjon enten psilocybin eller niacin før overkrysning (14). Alle pasientene fylte kriterier for en psykisk lidelse ifølge DSM-IV-systemet: 9o \% hadde tilpasningsforstyrrelse og $10 \%$ hadde generalisert angstlidelse. Det ble funnet signifikante forskjeller mellom gruppene før overkrysning, både for angst og depresjon. Seks måneder etter behandling hadde fortsatt $60-80 \%$ av pasientene respondert på psilocybin ut ifra Becks depresjonsskala og Hospital Anxiety and Depression Scale (HADS).

\section{DEPRESJON}

En stor del (20-30 \%) av pasienter med unipolar depresjon er behandlingsresistente (2). I en åpen studie av 12 pasienter med behandlingsresistent depresjon, definert som ingen bedring etter minst seks ukers behandling med minst to typer antidepressiver, gjorde psilocybin (9) at åtte av 12 pasienter oppnådde remisjon målt med Quick Inventory of Depressive Symptoms (QIDS) en uke etter behandlingen. Ved siste kontroll etter tre måneder var fortsatt 5 av 12 pasienter i remisjon, og 7 av 12 viste fortsatt respons (9).

En åpen studie av ayahuasca med seks pasienter som hadde tilbakevendende depresjon, demonstrerte umiddelbar antidepressiv effekt som var statistisk signifikant og som vedvarte ved oppfølging én og tre uker (15) etter behandling. To uker etter behandlingen ble det sett en ikke-signifikant økning av symptomene. Siden ayahuasca består av både det psykedeliske stoffet N,N-dimetyltryptamin og en monoaminooksidasehemmer, og sistnevnte er en etablert gruppe av antidepressiver, er det utfordrende å studere potensiell antidepressiv effekt av ayahuasca. Det er vanskelig å se for seg omfattende bruk av ayahuasca i kliniske studier før det etableres en standardisert fremstilling av virkestoffene (4). 


\section{AVHENGIGHET}

I en åpen studie av psilocybin med ti pasienter med alkoholavhengighet ble alkoholkonsumet signifikant redusert fra utgangspunktet til oppfølgingen etter 36 uker (8).

I en åpen studie av psilocybin med 15 pasienter med behandlingsresistent tobakk/nikotinavhengighet (12) var 80 \% av deltagerne avholdende etter seks måneder. Dette ble bekreftet med objektive mål på røykeslutt.

\section{TVANGSLIDELSE}

I en åpen studie av psilocybin med ni pasienter med tvangslidelse opplevde de fleste av pasientene reduksjon av kjernesymptomene. Men manglende sammenheng mellom dose og respons, og dessuten effekt på den svært lave minstedosen, gjør at forventningseffekter er sannsynlig (13).

\section{BIVIRKNINGER}

Gjennomgangen viste at det ikke er rapportert om alvorlige bivirkninger i noen av de ni studiene. En oppsummering av åtte dobbeltblinde randomiserte kontrollerte studier med til sammen 110 friske frivillige viste at psilocybin ser ut til å tolereres godt: $7 \%$ av deltagerne i høydosegruppen opplevde akutte bivirkninger, men disse kunne håndteres ved hjelp av støttende helsepersonell og uten bruk av nødmedikasjon. Det var ingen bivirkninger på lang sikt (7).

Vedvarende psykotiske symptomer er svært sjeldne. Ved ett enkelt tilfelle blant 1200 friske frivillige var det en psykotisk reaksjon utover 48 timer, og denne personen hadde en enegget tvilling med schizofreni (20). Psykoselidelse hos deltager og første- eller annengradsslektning er eksklusjonskriterier for moderne studier (21). Vedvarende psykotiske symptomer har ikke blitt observert i de moderne studiene på feltet (8-16).

\section{Diskusjon}

Hovedfunnene fra studiene i denne litteraturgjennomgangen gir støtte til at én eller noen få doser med et klassisk psykedelisk stoff, oftest psilocybin, har umiddelbar og vedvarende effekt ved flere psykiske lidelser. Det er ikke rapportert om alvorlige bivirkninger i noen av de ni studiene. De to største randomiserte kontrollerte studiene $(10,14)$ kom uavhengig av hverandre til samme konklusjon, nemlig signifikant og vedvarende (seks måneders) effekt av psilocybin mot kreftrelatert angst og depresjon. Samlet viser studiene at psilocybin og LSD har effekt mot angst og depresjon ved livstruende sykdom $(10,11,14,16)$.

Alle de omtalte studiene har metodologiske begrensninger, enten knyttet til design, blinding, uklart definerte endepunkter, seleksjon av pasienter og/eller utvalgsstørrelse. Det er ikke mulig å bekrefte hypoteser om psykedeliske stoffers effekt i åpne studier uten kontrollgruppe eller i åpne faser av randomiserte kontrollerte studier. Det er også vanskelig å skille medikamenteffekter fra psykologisk behandling gitt i kombinasjon uten kontrollarm. Videre viser gjennomgangen at det er vanskelig å bruke resultatene fra nåværende studier som grunnlag for endring av klinisk praksis.

Resultatene tyder på at psykedeliske stoffer har en potensiell klinisk effekt med lite bivirkninger i en kontrollert klinisk setting, og det er grunnlag for å gjøre systematiske studier med solid kvalitet. Det vil da være viktig å

- skille psykologisk fra farmakologisk effekt

- gjennomføre en protokoll uten seleksjonsskjevhet hos personell eller deltagere

- håndtere problemer knyttet til blinding og forventningseffekter, for eksempel ved bruk av lavdose fremfor ordinær placebo

- kontrollere for somatiske og psykiske bivirkninger akutt og som langtidseffekt (6) 
Psykedeliske stoffer må undersøkes i flere og større studier for å kunne fastslå klinisk effekt ved behandling av psykiske lidelser. Det vil være viktig å begrense psykologisk behandling til et minimum for å skille fra medikamenteffekt uten at det går ut over pasientens behov for tilstrekkelig trygghet og støtte.

Dersom de resultatene som foreligger kan bekreftes i fremtidige studier, vil umiddelbar og vedvarende effekt av én enkelt dose introdusere et nytt prinsipp i psykiatrisk behandling. Dette tilsvarer det som er observert ved utprøving av ketamin ved depresjon, selv om effekten der vedvarte i noen få uker (22). Mye tyder på at det kan være lurt å starte studier av psykedeliske stoffer nettopp på alvorlige depresjoner, slik som behandlingsresistent depresjon. Dette er et stort klinisk problem med få eller ingen effektive behandlingsalternativer (6).

Dagens antidepressive legemidler virker først etter noen uker og må tas daglig. Det vil være en fordel å få en raskere innsettende effekt. Vedvarende effekt av én enkelt dose vil gi fordeler sammenlignet med daglig administrerte medikamenter med tilhørende bivirkninger. Videre har psykedeliske stoffer en annen virkningsmekanisme enn dagens tilgjengelige antidepressiver, nemlig $5-\mathrm{HT}_{2 \mathrm{~A}}$-agonisme fremfor hovedsakelig monoaminreopptakshemming (4).

Det er nå flere fase II-studier av psykedeliske stoffer under planlegging eller gjennomføring ifølge databasen ClinicalTrials.gov. Psilocybin skal undersøkes ved depresjon, tvangslidelse og nikotin-, alkohol- og kokainavhengighet. LSD skal unders $ø$ kes ved angst med og uten livstruende sykdom (23). Dette er en spennende utvikling. Vi trenger nye evidensbaserte behandlingsalternativer for psykiske lidelser.

\section{HOVEDBUDSKAP}

Det er $ø$ kende interesse for kliniske studier av klassiske psykedeliske stoffer for behandling av psykiske lidelser

Klassiske psykedeliske stoffer ser ut til å ha liten risiko for alvorlige bivirkninger

Nylig er klassiske psykedeliske stoffer, særlig psilocybin, undersøkt i flere kliniske studier, med lovende resultater

Klassiske psykedeliske stoffer bør undersøkes i systematiske kliniske studier for å kartlegge behandlingspotensialet

\section{LITTERATUR:}

1. Grof S, Goodman LE, Richards WA et al. LSD-assisted psychotherapy in patients with terminal cancer. Int Pharmacopsychiatry 1973; 8: 129 - 44. [PubMed][CrossRef]

2. Rucker JJ, Jelen LA, Flynn S et al. Psychedelics in the treatment of unipolar mood disorders: a systematic review. J Psychopharmacol 2016;30: 1220 - 9. [PubMed][CrossRef]

3. Krebs TS, Johansen PØ. Lysergic acid diethylamide (LSD) for alcoholism: meta-analysis of randomized controlled trials. J Psychopharmacol 2012; 26: 994 - 1002. [PubMed][CrossRef]

4. Nichols DE. Psychedelics. Pharmacol Rev 2016; 68: 264-355. [PubMed][CrossRef]

5. Nutt DJ, King LA, Phillips LD. Drug harms in the UK: a multicriteria decision analysis. Lancet 2010; 376: 1558 - 65. [PubMed][CrossRef]

6. Carhart-Harris RL, Goodwin GM. The therapeutic potential of psychedelic drugs: past, present, and future. Neuropsychopharmacology 2017; 42: 2105 - 13. [PubMed][CrossRef]

7. Studerus E, Kometer M, Hasler F et al. Acute, subacute and long-term subjective effects of psilocybin in healthy humans: a pooled analysis of experimental studies. J Psychopharmacol 2011; 25: 1434 - 52.

[PubMed][CrossRef] 
8. Bogenschutz MP, Forcehimes AA, Pommy JA et al. Psilocybin-assisted treatment for alcohol dependence: a proof-of-concept study. J Psychopharmacol 2015; 29: 289 - 99. [PubMed][CrossRef]

9. Carhart-Harris RL, Bolstridge M, Rucker J et al. Psilocybin with psychological support for treatmentresistant depression: an open-label feasibility study. Lancet Psychiatry 2016; 3: 619 - 27.

[PubMed][CrossRef]

10. Griffiths RR, Johnson MW, Carducci MA et al. Psilocybin produces substantial and sustained decreases in depression and anxiety in patients with life-threatening cancer: A randomized doubleblind trial. J Psychopharmacol 2016;30: 1181 - 97. [PubMed][CrossRef]

11. Grob CS, Danforth AL, Chopra GS et al. Pilot study of psilocybin treatment for anxiety in patients with advanced-stage cancer. Arch Gen Psychiatry 2011; 68: 71 - 8. [PubMed][CrossRef]

12. Johnson MW, Garcia-Romeu A, Cosimano MP et al. Pilot study of the 5-HT2AR agonist psilocybin in the treatment of tobacco addiction. J Psychopharmacol 2014; 28: 983 - 92. [PubMed][CrossRef]

13. Moreno FA, Wiegand CB, Taitano EK et al. Safety, tolerability, and efficacy of psilocybin in 9 patients with obsessive-compulsive disorder. J Clin Psychiatry 2006; 67: 1735 - 40. [PubMed][CrossRef]

14. Ross S, Bossis A, Guss J et al. Rapid and sustained symptom reduction following psilocybin treatment for anxiety and depression in patients with life-threatening cancer: a randomized controlled trial. J Psychopharmacol 2016;30: 1165-80. [PubMed][CrossRef]

15. Osório FL, Sanches RF, Macedo LR et al. Antidepressant effects of a single dose of ayahuasca in patients with recurrent depression: a preliminary report. Rev Bras Psiquiatr 2015; 37: 13 - 20. [PubMed][CrossRef]

16. Gasser P, Holstein D, Michel Y et al. Safety and efficacy of lysergic acid diethylamide-assisted psychotherapy for anxiety associated with life-threatening diseases. J Nerv Ment Dis 2014; 202: 513 - 20. [PubMed][CrossRef]

17. Orsolini L, Papanti GD, De Berardis D et al. The “endless trip” among the NPS users: psychopathology and psychopharmacology in the hallucinogen-persisting perception disorder. a systematic review. Front Psychiatry 2017; 8: 240. [PubMed][CrossRef]

18. Krebs TS, Johansen РØ. Psychedelics and mental health: a population study. PLoS One 2013; 8: e63972. [PubMed][CrossRef]

19. Hendricks PS, Thorne CB, Clark CB et al. Classic psychedelic use is associated with reduced psychological distress and suicidality in the United States adult population. J Psychopharmacol 2015; 29: 280 - 8. [PubMed][CrossRef]

20. Cohen S. Lysergic acid diethylamide: side effects and complications. J Nerv Ment Dis 1960; 130:30 40. [PubMed][CrossRef]

21. Johnson M, Richards W, Griffiths R. Human hallucinogen research: guidelines for safety. J Psychopharmacol 2008; 22: 603 - 20. [PubMed][CrossRef]

22. Quintana DS, Steen NE, Andreassen OA. The promise of intranasal esketamine as a novel and effective antidepressant. JAMA Psychiatry 2018; 75:123 - 4. [PubMed][CrossRef]

23. ClinicalTrials.gov. U.S. National Library of Medicine.

https://www.clinicaltrials.gov/ct2/results?cond=\&termpsychedelic\&cntry=\&state=\&city=\&dist (30.8.2018).

Publisert: 12. november 2018. Tidsskr Nor Legeforen. DOI: 10.4045/tidsskr.17.1110

Mottatt 20.12.2017, første revisjon innsendt 12.1.2018, godkjent 30.8.2018.

(C) Tidsskrift for Den norske legeforening 2020. Lastet ned fra tidsskriftet.no 